\title{
The role of phonology in a letter detection task
}

\author{
JENNIFER GROSS \\ Grand Valley State University, Grand Rapids, Michigan \\ and \\ REBECCA TREIMAN and JOE INMAN \\ Wayne State University, Detroit, Michigan
}

\begin{abstract}
In two experiments, we investigated whether onsets and rimes have a role in the processing of written English. In both experiments, participants detected letter targets (e.g., $t$ ) in nonwords like vult faster than in nonwords like vust. This finding is consistent with Selkirk's (1982) view that sonorants (e.g., the /l/ of vult) cohere with preceding short vowels and are part of the vowel nucleus. In contrast, the / $t$ / of vust is part of the syllable's coda st and so is harder to isolate. Experiment 2 demonstrated that the time required for one to detect single-member codas following vowel digraphs (e.g., the $t$ in veet) was similar to the time to detect the same target letter following a postvocalic sonorant (e.g., the $t$ in vult). No evidence was found for onsets. The results provide support for a phonological organization among letters of printed rimes.
\end{abstract}

A major goal of psycholinguistics is to understand the units involved in the processing of spoken and written English. In speech processing, one level of analysis of analysis is the word. Spoken words also are divisible into syllables and phonemes. Compatibly, English orthography has a lexical level (represented by the spaces between words) and a graphemic level where a letter or a group of letters represents a single sound. Whole words map to complete phonological representations (e.g., aisle $\rightarrow$ /ail/). Graphemes map to individual phonemes (e.g., $c k \rightarrow / k /$ ). Grapheme-phoneme correspondences may exist at an intermediate level, larger than individual graphemes but smaller than words (e.g., break $\rightarrow /$ br/ + /eik/). This hypothesis is investigated in the present study.

\section{Units between Syllables and Phonemes in Spoken English}

In recent theories of syllable structure, the spoken syllable is viewed as more than a mere string of phonemes. Many linguists (Fudge, 1969; MacKay, 1972; Selkirk, 1982; Vergnaud \& Halle, 1979) postulate at least one level of representation intermediate between phonemes and syllables. According to this bipartite view of the spoken syllable, there is an intermediate division of a syllable whereby some phonemic sequences within a syllable are more cohesive than others. According to this view, the syllable

This research is part of a doctoral dissertation and was presented in part, at the meeting of the Midwestern Psychological Society in May 1995. The first author gratefully acknowledges the support of her doctoral committee members, John Mullennix, Martha Ratliff, and Doug Whitman. This work was supported in part by NSF Grant SBR-9408456 to R. Treiman. Correspondence concerning this article should be addressed to J. Gross, Psychology Department, Grand Valley State University, 292 Au Sable Hall, Allendale, MI 49401-9401(e-mail: grossj@ gvsu.edu). /breik/ can be broken into onset /br/ (initial consonant or consonant cluster) and rime /eik/ (vowel nucleus and final consonant or consonant cluster). These intermediate units are further divisible into phonemes.

Another view of the spoken syllable, the tripartite view, contends that the organization of phonemes within a syllable reflects a perceptual characteristic called the "sonority sequencing principle" (Bloomfield, 1933; Clements \& Keyser, 1983). According to this view, oscillating patterns of sonority govern the preferred order of segments within the syllable, and the primary divisions of the spoken syllable are onset, peak (vowel nucleus), and coda (final consonant or consonant cluster) (Clements \& Keyser, 1983). Thus, the syllable /breik/ comprises the onset/br/, peak/ei/, and coda $/ \mathbf{k} /$.

The distinguishing characteristic of the bipartite view of the spoken syllable (Fudge, 1969; MacKay, 1972; Selkirk, 1982; Vergnaud \& Halle, 1979) is the implication that the relationship between peak and coda (together, in the bipartite view, the rime) is closer than that between peak and onset. In contrast, proponents of the tripartite view claim that there is no persuasive evidence for the spoken rime. In this view, distributional constraints between the nucleus and the coda are as common as co-occurrence restrictions between the nucleus and the onset (the body) (Clements \& Keyser, 1983).

The bipartite view and the tripartite view are not entirely incongruent. According to the tripartite view, phonemic segments are arranged so that more sonorous segments are closer to the center of the syllable, and less sonorous segments are farther away (Clements \& Keyser, 1983). The nucleus, which is the sonorous peak of a syllable, corresponds to the beginning of a syllable's rime and the end of a syllable's body. Troughs in sonority correspond to syllable beginnings and ends. Thus one could, using the peak and troughs in the sonority cycle, parse the cycle into dis- 
crete units-body + coda (e.g., $/$ brei $/+/ \mathrm{k} /)$ as in the tripartite view, and onset + rime $(/ \mathrm{br} /+/ \mathrm{eik} /)$ as in the bipartite view.

Experimental investigations generally support the bipartite view, in which onsets and rimes are important units in speech processing (MacKay, 1972, 1978; Stemberger, 1983 ) and working memory (Treiman \& Danis, 1988). For example, segments such as syllable-initial consonant clusters appear to be units in naturally occurring (MacKay, 1972) and experimentally induced (MacKay, 1978) speech errors. In addition, the findings of developmental studies (Kirtley, Bryant, Maclean, \& Bradley, 1989; Knafle, 1974; Stanovich, Cunningham, \& Cramer, 1984; Treiman, 1985a, 1985b, 1993; Treiman, Zukowski, \& Richmond-Welty, 1995) and metalinguistic studies (Cutler, Butterfield, \& Williams, 1987; Treiman, 1983, 1984, 1986; Treiman, Salasoo, Slowiaczek, \& Pisoni, 1982) support the role of onset and rime units in spoken English. Onset and rime blendings also occur naturally in English; consider the origins of brunch (a meal served between breakfast and lunch).

Selkirk (1982) further postulated that spoken syllable structure differs as a function of vowel type ("short" [lax] or "long" [tense]) and of following consonant type (sonorant vs. obstruent, coronal vs. noncoronal). Sonorant consonants have a higher degree of articulatory opening than obstruent consonants do. Vowels, glides (transitional vowel sounds as in the word /haus/), liquids (/1/ and $/ \mathbf{r} /$ ), and nasals $(/ \mathrm{m} /, / \mathrm{n} /, / \mathrm{n} /)$ are classified as sonorants. Obstruents (e.g., $/ \mathrm{t} /, / \mathrm{d} /, / \mathrm{b} /, / \mathrm{p} /$ ) are less sonorous because such sounds are made by obstructing the vocal tract. In Selkirk's view, a syllable peak contains two potential positions that may be occupied by a short vowel and a sonorant liquid or nasal. Because long vowels occupy both positions in the syllable nucleus, any following nasals or liquids must be part of the coda (Fudge, 1969; Selkirk, 1982; Vergnaud \& Halle, 1979). Coda membership is limited at the most to two consonants. If two consonants occupy a syllable's coda, the second must be a coronal consonant (Selkirk, 1982). Coronals (e.g., /t/, /d/, /n/) are pronounced with the tip of the tongue turned upward toward the roof of the mouth.

Researchers have tested the predictions of Selkirk's (1982) theory by analyzing the vowel nucleus and its relationship to sonorant consonants that follow in a spoken syllable (Derwing \& Nearey, 1990; Treiman, 1984). The findings show that sonorants and glides are linked with a preceding vowel and are relatively separable from following consonants. Similarly, in spontaneous speech errors, postvocalic liquids $(/ \mathbf{r} /$ and $/ \mathbf{l} /)$ tend to cohere with the preceding vowel (Stemberger, 1983). A similar phenomenon appears in blending tasks (Gross, 1992; Treiman, 1984) and other metalinguistic tasks (Fowler, Treiman, \& Gross, 1993). Even evidence from children's spellings supports the idea that postvocalic consonants differ in their affinity with vowels (Read, 1975, 1986; Treiman, 1993; Treiman, Zukowski, \& Richmond-Welty, 1995). For adults, some short-term memory studies (Treiman \& Danis,
1988) have revealed greater cohesion between vowels and sonorants that follow them than between vowels and obstruents that follow them, whereas other studies (Treiman, 1995) have not. For children, there is some evidence that vowels and liquids are especially cohesive when the vowels are long (Treiman, 1995), contrary to Selkirk's (1982) predictions.

In sum, substantial evidence suggests that onsets and rimes are important units in speech processing. There is also some evidence that the structure of the rime unit depends partly on the nature of its phonological members.

\section{Units Between Syllables and Phonemes in Written English}

Because of the close correspondence between spoken and written English, one might wonder how this correspondence plays a role in reading. Orthographic units in reading may emerge because grapheme-phoneme correspondences exist at an intermediate level, larger than individual graphemes but smaller than words (e.g., break $\rightarrow$ $/ \mathrm{br} /+/ \mathrm{eik} /)$. Although this issue has been investigated in numerous studies, the results have been inconsistent.

Some support has been found for onset and rime units in printed word recognition (Treiman, 1994; Treiman \& Chafetz, 1987). Bowey (1990), however, has argued that such findings may reflect the special status of onsets and rime units in working memory rather than their role in reading. Other findings have supported the role of rime units in printed word recognition (Bowey, 1990, 1993, 1996; Treiman, Mullennix, Bijeljac-Babic, \& RichmondWelty, 1995; Treiman \& Zukowski, 1988). For example, Bowey $(1990,1993,1996)$ found that primes were effective when they corresponded to the rime of a word (e.g., ail priming hail), but not when they corresponded to a nonlinguistic constituent (e.g., ray priming pray). Unfortunately, methodological limitations, including the use of phonologically ambiguous primes (like bi priming birch; consider $\underline{b i k e})$, leave some of Bowey's earlier $(1990,1993)$ findings tenuous.

Other research has not yielded evidence for a special role for onsets and rimes in word recognition. Forster and Taft (1994) found priming effects for rime primes (e.g., paid-yaid; referred to as "body primes") as well as for body primes (an onset + vowel unit as in sail-saip; referred to as antibody primes), and for an "everything but the vowel" prime (as in ploin-plain). Similarly, Taraban and McClelland (1987) found equivalent priming effects for rime primes and onset + vowel (body) primes. However, rime primes were more likely to influence nonword pronunciations. Although Santa, Santa, and Smith (1977) produced evidence for orthographic onsets and rimes in word recognition, units such as consonant-consonantvowel sequences (bodies) and whole words had a comparable status. Thus, bla (the body) and ast (the rime) primed blast as effectively as $b l$ (the onset) did. Silverman (1985) failed to replicate Santa et al.'s findings, however. Levitt, Healy, and Fendrich (1991) also did not find support for the breaking of printed syllables into onset and rime. How- 
ever, Healy and her colleagues found some support for the division of the printed rime into smaller units-a nucleus and a coda.

Early readers' reliance on phonology during reading may not support the role of onset and rime units in printed word recognition. Duncan, Seymour, and Hill (1997; Experiment 2) found that beginning readers who were translating letters to sound in nonwords relied more on letters corresponding to onsets, peaks, and codas than on letters corresponding to rimes and bodies, even though the children had demonstrated a sensitivity to rhyme in an oral task. Furthermore, when beginning readers were asked to identify the phonological overlap between pairs of real words, they were more accurate at detecting bodies than rimes. They were also more accurate at detecting smaller units like single-phoneme onsets and codas than larger units like consonant cluster onsets and cluster codas (Duncan et al., 1997; Experiment 3).

Thus, previous research has not provided a clear answer to the question of whether onsets and rimes are functional units in the recognition of print. Most researchers (e.g., Bowey, 1990, 1993; Forster \& Taft, 1994; Taraban \& McClelland, 1987; Treiman, 1994; Treiman \& Chaftez, 1987; Treiman \& Zukowski, 1988; Treiman, Zukowski, \& Richmond-Welty, 1995) have attempted to address this issue by using a speech-based task such as word naming. However, overt naming studies may provide more information about the units in spoken English than about the units used in the recognition of printed words. In the experiments reported here, we utilized a letter detection task, thus avoiding the interpretive ambiguities associated with production tasks.

In Experiments 1 and 2, we investigated the use of orthographic onsets and rimes in visual word recognition. Because the spoken rime is composed of two membersa vowel and a following consonant or consonant clusterour evaluation of rime-like units in visual word recognition assessed the role of both members. In addition, in Experiment 1 we investigated whether onsets function as cohesive linguistic units in a letter detection task.

\section{EXPERIMENT 1}

Participants in a letter detection task saw nonwords such as bink and brid, followed by the target letter $b$. We hypothesized that participants would be quicker and more accurate to respond "yes" to $b$ in nonwords like bink than in nonwords like brid. This finding would be consistent with linguistic and psycholinguistic evidence suggesting that the $b$ of bink is a linguistic constituent-the syllable's onset. In contrast, the $b$ of brid is only part of the syllable's onset and thus should be harder to isolate in a letter detection task.

In addition, Experiment 1 pitted short vowel rimes with obstruent-obstruent (OO) final clusters against rimes with sonorant-obstruent ( $\mathrm{SO}$ ) clusters. Thus, other critical experimental trials were those in which the target letter appeared in the final position of the nonwords. For example, participants viewed nonwords like poft and pilt and then the target letter $t$. We predicted that participants would be quicker to respond "yes" to $t$ in nonwords like pilt than in nonwords like poft, because the $t$ of pilt is a linguistic constituent. In comparison, the $t$ of poft is only part of the syllable's coda ( $f t$ ) and should be harder to isolate.

\section{Method}

Participants. Nineteen students who were enrolled in undergraduate psychology classes at Wayne State University participated in exchange for course credit. All participants in this and the following experiment were native English speakers and had normal or corrected-to-normal vision.

Materials. The stimuli were carefully constructed to control for factors that may affect reading times. In English, spellings often have more than one pronunciation (e.g., have vs. gave; get vs. gin). The mapping of pronunciation to spelling also is not consistent; thus bait, eight, and hate have the same phonological rime but different spellings. To avoid these factors, we included the rime consistency controls used by Stone, Vanhoy, and Van Orden (1997) and we included only orthographically and phonologically consistent onsets. Reading times also could be influenced by the number of letters, graphemes, and phonemes in words and nonwords, and by the presence of homophones and pseudohomophones. We controlled for these factors.

Using a computer program specifically prepared for these experiments, a corpus of 17,068 nonwords was produced that represented all possible monosyllabic nonwords in English that had consistent pronunciations but were not pronounced like real words. In an effort to ensure that the nonwords could be pronounced, only valid English onsets and rimes were used in their construction. English onsets can have zero, one, two, or three letters. An onset list used for the construction of the corpus contained all English onsets that had one-toone correspondence between letters and phonemes. Onsets like $t h$ were not used, because such a multiletter grapheme maps onto a single phoneme. In addition, onsets with more than one phonological representation (e.g., g) were not used. A separate list, the rime list, was composed of all English rimes that have a consistent pronunciation. Also, each letter in the rime mapped to a single sound in speech. Thus, digraphs in which two letters represent one sound (e.g., $c k$ ) were avoided. To formulate the rime list, a dictionary of rhyming words (Words to Rhyme With, 1986) was used. For every phonological rime (e.g., /eit/), all possible spellings were identified (e.g., ait, eight, and ate), and those with multiple spellings were not used. Similarly, for every graphemic rime, all phonological rimes were identified, and those with multiple pronunciations were not used. For example, the orthographic rime ave has more than one phonological representation and was not used. The generated rime list was further filtered using a list of consistent rimes found in Stanback (1991). All experimental nonwords were selected from this corpus.

The experimental stimuli that were constructed for the investigation of the role of orthographic onsets contained four graphemes that mapped onto four phonemes. There were $16 \mathrm{CVCC}$ nonwords like dalf and 16 CCVC nonwords like drem (see Appendix A). These stimuli were matched for initial grapheme, average bigram frequency of the first two letters (averaged across word lengths of two through nine letters; Solso \& Juel, 1980), and average bigram frequency of the whole nonword. The average bigram frequency of the first two letters was 498.3 for CVCCs and 592.9 for CCVCs. This slight advantage for CCVCs favored the nonwords, which were ex- 
pected to cause more difficulty in the detection task, and it was due to two stimuli that had an extremely common consonant cluster. The average bigram frequency of the entire nonword was $2,781.6$ for CVCCs and 2,656.5 for CCVCs.

To investigate the nature of rimes in printed word recognition, other experimental stimuli contained four graphemes that mapped to four phonemes and had the form CVCC. Sixteen stimuli contained an $O O$ (obstruent-obstruent) final cluster (e.g., doft), and 16 stimuli contained an SO (sonorant-obstruent) cluster (e.g., dilt) (see Appendix A). The OO clusters were $f t, c t, s k, s p$, and $p t$. The SO clusters were $l t, l p, r p$, and $r k$. These clusters were selected to ensure that the target letters $t, p$, and $k$ occurred equally among cluster types. The number of clusters available for investigation with comparable bigram frequencies was limited, because SO clusters are more common than OO clusters in four-letter English words. These stimuli were matched for final grapheme, average bigram frequency for the third and fourth letters (for word lengths of four letters), and average bigram frequency for the whole nonword. The average bigram frequency of the last two letters was 171.6 for nonwords like doft and 221.1 for nonwords like dilt. This slight tendency for SO clusters to be more common than $O O$ clusters was attributable to three stimuli that had the common cluster $r k$. The average bigram frequency for the entire nonword was 2,662.5 for nonwords like doft and 3,510.7 for nonwords like dilt. Again, the slight bias in favor of nonwords like dilt was attributable to three stimuli and not characteristic of the stimuli as a whole.

There were 64 critical trials, all requiring a "yes" response. There were 64 additional filler trials requiring a "yes" response, on which the target letter occurred equally often in the second and third positions. There were 88 filler trials requiring a "no" response. Like the experimental trials, the filler trials included an equal number of CVCC and CCVC nonwords.

Procedure. The participants were seated before an IBM XT with a monochrome monitor. The participants were informed that they would decide whether a target letter was present in a preceding nonword. They were informed that all of the "words" in the experiment were meaningless. Each trial began with presentation of a fixation point for $2,000 \mathrm{msec}$, followed by a $60-\mathrm{msec}$ blank interval. The nonwords, which were presented for $300 \mathrm{msec}$, appeared in the same location as the fixation point. The stimulus was subsequently replaced by one of four randomly selected patterned masks that appeared for $100 \mathrm{msec}$. The masks contained word-like characters. After $800 \mathrm{msec}$, the target letter appeared, centered in the middle of the screen, and remained on the screen until a response was initiated. The participants responded by pushing a " $y$ " button to indicate that the target letter was present in the nonword, or an " $n$ " button to indicate that it was not. Templates were used to aid the participants' responding. These templates had only two response keys visible The location of the " $y$ " and " $n$ " keys was counterbalanced across participants. Both speed and accuracy were stressed. Each participant received 8 practice trials followed by 216 experimental trials. The order of the stimuli was randomized for each participant.

\section{Results}

The trials of most interest were those on which letter targets appeared in the first and fourth positions of the nonwords. For each letter position, separate analyses were performed to evaluate reaction times (RTs) and error rates, with participants and items as random factors. For both experiments, $p \leq .05$, and only analyses significant by participants and by stimuli were considered robust. Thus, stimulus analyses will not be reported if participants analyses were nonsignificant.

For the first letter of the nonword, an analysis of variance (ANOVA) with the factor of onset length (CVCC vs.
$\mathrm{CCVC}$ ), and with repeated measure for participants but not for stimuli, showed that the average RT for correct detection of the initial grapheme (e.g., b) in CCVC stimuli (brid) $(634 \mathrm{msec}, S D=232)$ was not significantly different from the correct detection of the initial grapheme (e.g., $b$ ) in CVCC stimuli (bink) $(630 \mathrm{msec}, S D=232$; $F<1$ ). There also was no difference in error rates between CVCC stimuli (mean error rate $=1 \%, S D=0.11$ ) and CCVC stimuli (mean error rate $=3 \%, S D=0.17 ; F<1$ ). Thus, the results did not provide support for orthographic onsets.

For the fourth letter of the nonword, an ANOVA with the factor of cluster type (OO vs. $\mathrm{SO}$ ), and with repeated measures for participants but not for stimuli, showed that there was a main effect of cluster type across participants $\left[F(1,18)=14.2, M S_{\mathrm{e}}=99,444.4\right]$ and across stimuli $\left[F(1,30)=90.4, M S_{\mathrm{e}}=22\right]$. Participants detected the fourth letter faster in nonwords like dilt (average RT = $738 \mathrm{msec}, S D=261 \mathrm{msec}$ ), for which the target letter was part of an SO cluster, than in nonwords like doft (average $\mathrm{RT}=842 \mathrm{msec}, S D=441 \mathrm{msec}$ ), for which the target letter was part of an $\mathrm{OO}$ cluster. Thus, participants detected targets that alone were the syllables' codas faster than targets that were only part of the syllables' codas. Error analyses revealed no significant difference between CVCC stimuli (mean error rate $=6 \%, S D=0.24$ ) and CCVC stimuli $($ mean error rate $=7 \%, S D=0.25 ; F<1)$.

\section{Discussion}

The results of Experiment 1 suggest that the organization of printed rimes mirrors their phonological structure. Postvocalic cohesion appears to differ as a function of coda complexity (number of members) and consonant sonority. A dual-member coda such as $f t$ appears to be a constituent, and thus it was harder to isolate and detect a member of the unit than to detect a singleton coda. Postvocalic sonorants appear to have a closer affinity with preceding vowels than do postvocalic obstruents. Thus, target letters that followed postvocalic sonorants (e.g., $t$ after $l$ ) were more isolable than target letters that followed postvocalic obstruents (e.g., $t$ after $f$ ).

The data did not the support the hypothesis that participants would be slower to respond "yes" to $d$ in nonwords like drem than in nonwords like dalf. A second letter detection experiment (Gross, 1996) was conducted to reinvestigate the role of onsets in printed word recognition. ${ }^{1}$ Again, the results failed to show cohesion between consonants in dual-member onsets. Detection of an initial target letter was not more difficult when it was a member of an onset cluster than when it was a single-letter onset.

Although the findings suggest that the internal phonological structure of a rime in print is analogous to that of its oral counterpart, there is an alternative explanation. Postvocalic $c, s, p$, and $f$ were the obstruents used in the OO clusters. Only $r$ and $l$ were used as sonorants in the SO clusters on the grounds that $/ \mathbf{r} /$ and $/ 1 /$ are more "vowel sticky" than other sonorants (e.g., $/ \mathrm{m} /, / \mathrm{n} /)$ (Treiman, 1984, 1993; Treiman \& Danis, 1988). In filler trials, how- 
ever, the postvocalic sonorants $m, n, r$, and $l$ and postvocalic obstruents $c, s, p$, and $f$ were used equally often. The additional exposure to targets preceded by $r$ and $l$ (i.e., an extra 16/216 trials) could have caused faster detection times. In Experiment 2, we evaluated the structure of the printed rime while controlling for this potential confound.

\section{EXPERIMENT 2}

In Experiment 2, we again investigated whether coda complexity influences detection of a target. As in Experiment 1 , nonword-final $\mathrm{SO}$ and $\mathrm{OO}$ clusters were included. We expected detection of the word-final consonant letter to be quicker in $\mathrm{SO}$ clusters than in $\mathrm{OO}$ clusters. This finding would provide further evidence that postvocalic sonorants have a closer affinity with preceding vowels than do postvocalic obstruents.

Stimuli containing digraphs corresponding to tense vowels were also included so that we could evaluate detection of the target letter when it was the sole member of a syllable coda. We expected that detection of the target letter after a tense vowel digraph (e.g., $t$ in veet) would be similar to detection of the same target in a nonword-final SO cluster (e.g., $t$ in vult). Detection of the target in a complex coda (e.g., $t$ in vust) should lead to longer RTs because the target was part of a two-element coda in this case.

\section{Method}

Participants. Twenty-nine students from the same population as that which provided the participants in Experiment 1 served in exchange for course credit.

Materials. The experimental nonwords were again selected from the corpus of nonwords that excluded pseudohomophones, consonant digraphs, and inconsistent pronunciations. The experimental stimuli contained four graphemes representing four phonemes (i.e., CVCC nonwords) or four graphemes representing three phonemes (i.e., CVVC nonwords). Twelve stimuli contained an 00 cluster (e.g., vust) and 12 CVCC stimuli contained an SO cluster (e.g., vult). Twelve additional CVVC stimuli (e.g., veet) contained a vowel digraph followed by an obstruent coda. SO clusters and long vowels are common in four-letter English words. When letter groups are frequent in real words, few non-pseudohomophonic nonwords can be constructed that contain these groups, limiting the number of stimuli available for investigation.

The postvocalic sonorant in the SO clusters was $l$ or $r$, and the postvocalic obstruent in the OO clusters was $f$ or $s$. The stimuli were carefully matched on two of four letters across the three stimulus types. For example, vust, vult, and veet vary by only two letters (see Appendix B). The three types of stimuli were also matched for final grapheme, average bigram frequency of the last two graphemes, and the average bigram frequency of the whole nonword. The average bigram frequency of the two word-final graphemes was 1,309.3 for

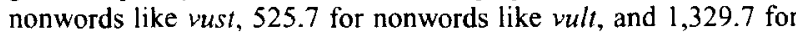
nonwords like veet. Within each of the stimulus types, there was one outlier that skewed the measure of central tendency. With the outliers removed, the average bigram frequencies of the two word-final graphemes were $351.1,401.2$, and 363.0 , respectively. The average bigram frequency of the entire nonword was $4,158.0$ for stimuli like vust, $4,318.5$ for stimuli like vult, and 4,924.9 for stimuli like veet.

There were 36 critical trials, all requiring a "yes" response. There were an additional 108 filler trials requiring a "yes" response on which the target letter occurred equally often in the first position (36 cases), second position ( 36 cases), and third position ( 36 cases). There were 96 filler trials requiring a "no" response. Like the experimental trials, the filler trials presented an equal number of CVCC, CCVC, and CVVC nonwords.

Procedure. The procedure was the same as in Experiment 1.

\section{Results}

The trials under investigation were those containing letter targets appearing in the fourth position of the nonwords. Separate analyses were performed to evaluate RTs and error rates with participants and items as random factors. Three participants' data were removed because of high error rates (average error rates of $17 \%$ or greater for at least one stimulus type).

In detection of the fourth letter of the stimuli, an ANOVA with the factor of cluster type (with repeated measures for participants and for stimuli) showed a main effect of cluster type by participants $\left[F(2,50)=3.6, M S_{\mathrm{e}}=44,370.9\right]$ and by stimuli $\left[F(2,22)=4.05, M S_{\mathrm{e}}=1,566.0\right]$. As predicted, detection of the fourth letter was faster in SO clusters (e.g., vult) (average RT $=700 \mathrm{msec}, S D=247 \mathrm{msec}$ ) than in OO clusters (e.g., vust) (average RT $=745 \mathrm{msec}$, $S D=287 \mathrm{msec})\left[F(1,25)=5.5, M S_{\mathrm{e}}=54,490.8\right.$ by participants; $F(1,11)=11.7, M S_{e}=2,056.4$ by stimuli]. Also, participants' responses to $t$ in nonwords like vult did not differ significantly from their responses to $t$ in nonwords like veet (average RT $=714 \mathrm{msec}, S D=304 \mathrm{msec})(F<1)$.

There was no difference in error rates for detection of the target letter in SO clusters (mean error rate $=4 \%, S D=$ 0.22 ), OO clusters (mean error rate $=3 \%, S D=0.24$ ), or nonclusters (i.e., CVVC stimuli) (mean error rate $=4 \%$, $S D=0.24)(F<1)$.

\section{Discussion}

We hypothesized that participants would be quicker to respond "yes" to $t$ in nonwords like vult than in nonwords like vust. They were. This finding is consistent with linguistic and psycholinguistic evidence which suggests that the $t$ of vult corresponds to a linguistic constituent (the syllable's coda) because the sonorant $/ 1 /$ is part of the vocalic nucleus. In comparison, the $t$ of vust is part of the syllable's coda st and thus should be harder to isolate in a letter detection task. If the coda is a real unit, a task that preserves this unit should be easier than a task that involves only part of the constituent. The results confirmed this hypothesis.

We also hypothesized that detection of the target following a vowel digraph (e.g., the $t$ of veet) should be similar to its detection following a postvocalic sonorant (e.g., the $t$ of volt). According to Fudge (1969) and Selkirk (1982), the targets in both of these stimuli correspond to a singleton coda. The results confirmed this prediction, supporting the role of phonological constituents in nonword recognition.

\section{GENERAL DISCUSSION}

The present experiments provide evidence for a level of analysis in visual word recognition that corresponds to a 
level of analysis found in spoken English. Specifically, there appears to be an internal organization among letters within a printed rime, determined in part by the letters' phonological attributes. In spoken English, a phonological rime has two members, a vocalic nucleus and a syllablefinal coda (Clements \& Keyser, 1983; Selkirk, 1982). Similarly, our findings suggest that printed rimes have two parts, a vowel unit and a coda unit. In printed word recognition, vowel letters are necessarily coded as members of the phonological vowel unit. In addition, our findings suggest that letters corresponding to sonorant consonants following a vowel compose part of the nucleus. In contrast, letters corresponding to postvocalic obstruents appear to be classified as part of the graphemic coda.

In addition, the findings of Experiment 2 demonstrate that the detection of a letter corresponding to a singlemember coda following a vowel digraph (e.g., the $t$ of veet) leads to RTs similar to those for the detection of the same target letter following a postvocalic sonorant (e.g., the $t$ in vult). This similarity suggests that in both cases the target letter occupies a single seat in the graphemic coda. Detection of the identical target in nonwords like $v u c t$ took significantly longer, presumably because the target letter corresponded to a phoneme that was a constituent of the syllable's cluster coda $c t$. Thus, Experiment 2 provides another demonstration that the codes used in the letter detection task mirror, in part, the codes found in speech perception.

Previous research (Levitt et al., 1991; Treiman, 1994) has provided some preliminary support for the idea that a printed rime can be broken into a peak and a coda unit, and that the location of this break is determined by the sonority of the postvocalic consonant. The evidence from both of these studies is weak, however, perhaps because the tasks lacked sensitivity. The researchers interrupted the reading process by using asterisks (Levitt et al., 1991) or slashes (Treiman, 1994) embedded in words, which may not have not sufficiently disrupted the integrity of the letter groups.

Our findings support the general view of reading which suggests that one possible route to stored meanings in memory is based on the translation of printed words to speech-based codes (e.g., Glushko, 1979; Lukatela \& Turvey, 1994; Meyer, Schvaneveldt, \& Ruddy, 1974; Perfetti \& Bell, 1991; Perfetti, Bell, \& Delaney, 1988; Pollatsek, Lesch, Morris, \& Rayner, 1992; Rubenstein, Lewis, \& Rubenstein, 1971; Stone et al., 1997; Van Orden, 1987; Van Orden, Johnston, \& Hale, 1987; Van Orden, Pennington, \& Stone, 1990; Ziegler \& Jacobs, 1995). The English writing system is an alphabet. In an alphabetic system, graphemes represent the individual phonemes of the spoken language. In English, the relations between graphemes and phonemes are not one-to-one. Rather, a single phoneme can have several spellings (e.g., $/ \mathrm{k} /$ as in $\underline{c} a t, b a \underline{k e}$, and back), and two or more phonemes can be spelled with the same grapheme (e.g., consider / $/$ / and $/ \theta /$ in then and thin, respectively). Our findings suggest that graphemic parsing is influenced by the phonological char- acteristics of the letters. It has been suggested that rimes play a role in reading, in part because relations between graphemes and phonemes are more consistent at this level than at the level of smaller units (see Treiman, Zukowski, \& Richmond-Welty, 1995). Our data support cohesive letter units such as vowel units and coda units in the processing of written nonwords.

Like rimes, onsets appear to be important units in speech processing and may also be units in printed word recognition. Onsets were also the focus of Experiment 1 and the experiment by Gross (1996). These experiments were investigations of whether initial letters corresponding to a syllable's onset would be found to function as cohesive linguistic units in a letter detection task. We hypothesized that participants would be quicker and more accurate to respond "yes" to $b$ in nonwords like bink, where the target letter corresponds to the syllable's onset, than in nonwords like brid, where the target letter is only part of the syllable's onset $b r$. However, the results revealed no difference in detection speed for the two types of nonwords.

Why did we not find evidence for the existence of graphemic onsets? Our null results may reflect a lack of sensitivity of the letter detection task. Detection times for initial letter targets were very quick, around $600 \mathrm{msec}$, and may have masked an onset effect. In a future investigation, one could consider syllable-initial onsets that are not word initial. For example, one could investigate whether the target letter $d$ is easier to detect in the nonword semi-dalf than in the nonword semi-drem. Another possibility is that our null results reflect a control that was implemented in the selection of the stimuli. We equated experimental stimuli (e.g., blid) and control stimuli (e.g., bink) for initial target letter (e.g., $b$ ) and average bigram frequency of the target letter and the following letter (e.g., $b l, b i$ ), among other things. In English, word-initial $\mathrm{CV}$ units have a much wider range of frequencies than do word-initial $\mathrm{CC}$ units. To equate control and experimental stimuli, we had to sample less common CVs, which are a small portion of the natural distribution of CVs. This use of more common CV units may have shown easier separation of the onset from the vowel, resulting in faster detection times. Finally, it is possible that onsets are not a primary constituent in written English. In accordance with the tripartite view of spoken syllables, the mappings from graphemes to phonemes may represent units like bodies and codas. Or, printed words may be divided into larger, overlapping units like bodies and rimes. Our data do not allow one to distinguish between these propositions.

A possible limitation of our work is the use of long delays between the presentation of nonwords and targets. This delay could bias phonological conversions of the printed nonwords (Hawkins, Reicher, Rogers, \& Peterson, 1976). Such a strategic response to the demands of the experiment might not reveal the nature of letter-to-sound conversions used in normal reading. In future studies, the timing between presentation of nonwords and targets could be varied systematically. If, for example, detection 
differences for $t$ in vult and in vust were found to remain at short stimulus onset asynchronies (SOA), such findings would likely reveal the process whereby letter strings are converted to grapheme strings made of single graphemes (e.g., $c k$ ) or multigrapheme groupings (e.g., $b+a c k$ ) which map to phonology. If, however, such patterns of responses were revealed only under long SOAs $(1,200 \mathrm{msec}$ as in the present experiments), the results might say more about the phonological codes used in working memory than the codes used in printed word recognition. ${ }^{2}$ Support for the separation of graphemic parsing and grapheme-tophoneme processing comes from a case study of a phonological dyslexic (see Coltheart, 1996), who showed selective impairment in the former but not latter process.

Although we cannot draw firm conclusions from these results about orthographic onsets, we have found something new about the nature of orthographic rimes. The results of both Experiments 1 and 2 support an internal organization among the letters of printed rimes. There appears to be a hierarchical structure of letters in print, whereby some sequences within the rime of a monosyllabic nonword are more cohesive than others. For example, the $u$ and $l$ of vult are more cohesive than the $u$ and $s$ of vust. Our results support a form of phonological codes used in the recognition of words in print that mirrors the form of the codes found in the analysis of spoken English. This correspondence appears to exist at a subsyllabic level. Although a full understanding of intrasyllabic units in visual word recognition is still unfolding, our results support a level of representation that is similar to a phonological vowel and coda unit in spoken English.

\section{REFERENCES}

Bloomfield, L. (1933). Language. New York: Holt.

BOWEY, J. A. (1990). Orthographic onsets and rimes as functional units of reading. Memory \& Cognition, 18, 419-427.

BOWEY, J. A. (1993). Orthographic rime priming. Quarterly Journal of Experimental Psychology, 40A, 247-271.

BowEY, J. A. (1996). Phonological recoding of nonword orthographic rime primes. Journal of Experimental Psychology: Learning, Memory, \& Cognition, 22, 117-131.

Clements, G. N., \& Keyser, S. J. (1983). CV phonology: A generative theory of the syllable. Cambridge, MA: MIT Press.

Coltheart, M. (1996). Phonological dyslexia: Past and future issues. Cognitive Neuropsychology, 13, 749-762.

Cutler, A., Butterfield, S., \& Williams, J. N. (1987). The perceptual integrity of syllabic onsets. Journal of Memory \& Language, 26, 406-418.

Derwing, B. L., \& Nearey, T. M. (1990, November). Real-time effects of some intrasyllabic collocational constraints in English. Paper presented at the meeting of the International Conference on Spoken Language Processing, Kobe, Japan

DunCan, L. G., Seymour, P. H. K., \& Hill, S. (1997). How important are thyme and analogy in beginning reading? Cognition, 63, 171-208.

FORSTER, K. I., \& TAFT, M. (1994). Bodies, antibodies, and neighborhooddensity effects in masked form priming. Journal of Experimental Psychology: Learning, Memory, \& Cognition, 20, 844-863.

Fowler, C., Treiman, R., \& Gross, J. (1993). The structure of English syllables and polysyllables. Journal of Memory \& Language, 32, 115 140.

FUdGE, E. C. (1969). Syllables. Journal of Linguistics, 5, 253-286.

GLUSHKo, R. (1979). The organization and synthesis of orthographic knowledge in reading aloud. Journal of Experimental Psychology: Human Perception \& Performance, 5, 674-691.
Gross, J. (1992). The hierarchy of the syllable: Evidence from polysyllabic nonwords. Unpublished master's thesis, Wayne State University. GRoss, J. (1996). Not all letters are alike: The role of phonology in reading. Dissertation Abstracts International, 57 (4-A), 1483. (UMI Microform No. 9628895).

Hawkins, H. L., Reicher, G. M., Rogers, M., \& Peterson, L. (1976). Flexible coding in word recognition. Journal of Experimental Psychology: Human Perception \& Performance, 2, 380-385.

Kirtley, C., Bryant, P., Maclean, M., \& Bradley, L. (1989). Rhyme, rime, and the onset of reading. Journal of Experimental Child Psychology, 48, 224-245.

KNAFLE, J. D. (1974). Children's discrimination of rhyme. Journal of Speech \& Hearing Research, 17, 367-372.

LevitT, A., Healy, A. F., \& Fendrich, D. W. (1991). Syllable-internal structure and the sonority hierarchy: Differential evidence from lexical decision, naming, and reading. Journal of Psycholinguistic Research, 20, 337-363.

Lukatela, G., \& Turvey, M. T. (1994). Visual lexical access is initially phonological: Evidence from associative priming by words, homophones, and pseudohomophones. Journal of Experimental Psychology: General, 123, 107-128.

MacKAY, D. G. (1972). The structure of words and syllables: Evidence from errors in speech. Cognitive Psychology, 3, 210-227.

MacKAY, D. G. (1978). Speech errors inside the syllable. In A. Bell \& J. B. Hooper (Eds.), Syllables and segments (pp. 201-212). Amsterdam: North-Holland.

Meyer, D. E., Schvaneveldt, R. W., \& Ruddy, M. G. (1974). Functions of graphemic and phonemic codes in visual word-recognition. Memory \& Cognition, 2, 309-321.

Perfetti, C. A., \& BeLl, L. (1991). Phonemic activation during the first $40 \mathrm{~ms}$ of word identification: Evidence from backward masking and priming. Journal of Memory \& Language, 30, 473-485.

Perfetti, C. A., Bell, L., \& Delaney, S. (1988). Automatic phonetic activation in silent word reading: Evidence from backward masking. Journal of Memory \& Language, 27, 59-70.

Pollatsek, A., Lesch, M., Morris, R. K., \& Rayner, K. (1992). Phonological codes are used in integrating information across saccades in word identification and reading. Journal of Experimental Psychology: Human Perception \& Performance, 18, 148-162.

READ, C. (1975). Children's categorization of speech sounds in English (NCTE Research Report No. 17). Urbana, IL: National Council of Teachers of English.

READ, C. (1986). Children's creative spelling. London: Routledge \& Keegan Paul

Rubenstein, H., Lewis, S. S., \& Rubenstein, M. H. (1971). Evidence for phonemic recoding in visual word recognition. Journal of Verbal Learning \& Verbal Behavior, 10, 645-647.

Santa, J. L., Santa, C., \& Smith, E. E. (1977). Units of word recognition: Evidence for the use of multiple units. Perception \& Psychophysics, 22, 585-591.

SelkiRK, E. O. (1982). The syllable. In H. van der Hulst \& N. Smith (Eds.), The structure of phonological representations, (Pt. 1, pp. 337383). Dordrecht: Fusts.

Silverman, W. P. (1985). Two types of word superiority effects in a speeded matching task. Memory \& Cognition, 13, 50-56.

Solso, R. L., \& JUEL, C. L. (1980). Positional frequency and versatility of bigrams for two- through nine-letter English words. Behavioral Research Methods \& Instrumentation, 12, 297-343.

STANBACK, M. L. (1991). Syllable and rime patterns for teaching reading: Analysis of a frequency-based vocabulary of 17,602 words. Unpublished doctoral dissertation, Columbia University.

Stanovich, K. E., Cunningham, A. E., \& Cramer, B. (1984). Assessing phonological awareness in kindergarten children: Issues of task comparability. Journal of Experimental Child Psychology, 38, 175190.

Stemberger, J. P. (1983). The nature of $/ \mathrm{r} /$ and $/ \mathrm{l} /$ in English: Evidence from speech errors. Journal of Phonetics, 11, 139-147.

Stone, G. O., Vanhoy, M., \& Van Orden, G. C. (1997). Perception is a two-way street: Feedforward and feedback phonology in visual word recognition. Journal of Memory \& Language, 36, 337-359.

Taraban, R., \& MCClelland, J. L. (1987). Conspiracy effects in word pronunciation. Journal of Memory \& Language, 26, 608-631. 
Treiman, R. (1983). The structure of spoken syllables: Evidence from novel word games. Cognition, 15, 49-74.

TREIMAN, R. (1984). On the status of final consonant clusters in English syllables. Journal of Verbal Learning \& Verbal Behaviour, 23, 343 356

Treiman, R. (1985a). Onsets and rimes as units of spoken syllables: Evidence from children. Journal of Experimental Child Psychology, 39, 161-181.

Treiman, R. (1985b). Phonemic analysis, spelling, and reading. In T. H. Carr (Ed.), New directions for child development: The development of reading skills (Vol. 27, pp. 5-18). San Francisco: Jossey-Bass.

Treiman, R. (1986). The division between onsets and rimes in English syllables. Journal of Memory \& Language, 25, 476-491.

Treiman, R. (1993). Beginning to spell: A study of first-grade children. New York: Oxford University Press.

TREIMAN, R. (1994). To what extent do orthographic units in print mirror phonological units in speech? Journal of Psycholinguistic Research, 23, 91-110.

Treiman, R. (1995). Errors in short-term memory for speech: A developmental study. Journal of Experimental Psychology: Learning, Memory, \& Cognition, 21, 1197-1208.

Treiman, R., \& Chafetz, J. (1987). Are there onset- and rime-like units in written words? In M. Coltheart (Ed.), Attention and performance XII: The psychology of reading (pp, 281-298). Hillsdale, NJ: Erlbaum.

Treiman, R., \& DaNIS, C. (1988). Short-term memory errors for spoken syllables are affected by the linguistic structure of the syllables. Journal of Experimental Psychology: Learning, Memory, \& Cognition, 14, $145-152$.

Treiman, R., Mullennix, J., Bijeljac-Babic, R., \& RichmondWELTY, E. D. (1995). The special role of rimes in the description, use, and acquisition of English orthography. Journal of Experimental Psychology: General, 124, 107-113

Treiman, R., Salasoo, A., Slowiaczek, L. M., \& Pisoni, D. B. (1982)
Effects of syllable structure on adults' phoneme monitoring performance. Research on Speech Perception (Progress Report No. 8). Bloomington: Indiana University, Speech Research Laboratory.

Treiman, R., \& ZuKowsKi, A. (1988). Units in reading and spelling. Journal of Memory \& Language, 27, 466-477.

Treiman, R., Zukowski, A., \& Richmond-Welty, D. (1995). What happened to the " $n$ " of sink? Children's spelling of final consonant clusters. Cognition, 55, 1-38.

VAN ORDEN, G. C. (1987). A ROws is a ROSE: Spelling, sound, and reading. Memory \& Cognition, 15, 181-198.

VAN ORden, G. C., Johnston, J. C., \& Hale, B. L. (1987). Word identification in reading proceeds from spelling to sound to meaning. Journal of Experimental Psychology: Learning, Memory, \& Cognition, 14, 371-386.

Van Orden, G. C., Pennington, B. F., Stone, G. O. (1990). Word identification in reading and the promise of subsymbolic psycholinguistics. Psychological Review, 4, 488-522.

Vergnaud, J. R., \& Halle, M. (1979). Metrical phonology. Unpublished manuscript, Massachusetts Institute of Technology, Department of Linguistics.

Words to rhyme with (1986). London: MacMillan.

ZIEGLeR, J. C., \& JACOBS, A. M. (1995). Phonological information provides early sources of constraint in the processing of letter strings. Journal of Memory \& Language, 34, 567-593.

\section{NOTES}

1. The procedure used in Gross (1996, Experiment 1) was the same as in the studies described here, with one exception. The interval following presentation of the nonwords and subsequent patterned mask was $60 \mathrm{msec}$ as opposed to $800 \mathrm{msec}$.

2. The authors thank Roman Taraban for his ideas on varying delays between nonwords and targets.

APPENDIX A

Nonwords Used in Experiment 1

\begin{tabular}{lcccc}
\hline \multicolumn{2}{l}{ Target Letter in } & Position 1 & \multicolumn{2}{c}{ Target Letter in Position 4 } \\
\cline { 1 - 2 } $\begin{array}{c}\text { Onset } \\
\text { Length } 1\end{array}$ & $\begin{array}{c}\text { Onset } \\
\text { Length 2 }\end{array}$ & & $\begin{array}{c}\text { Obstruent-Obstruent } \\
\text { Cluster }\end{array}$ & $\begin{array}{c}\text { Sonorant-Obstruent } \\
\text { Cluster }\end{array}$ \\
\hline dalf & drem & doft & dilt \\
bin & blid & & poft & pilt \\
boft & brid & & gisp & forp \\
durp & drin & disp & torp \\
golt & grel & bept & vark \\
goft & grem & beft & selt \\
gomp & grob & vept & tark \\
peft & plid & bact & golt \\
pelm & prem & tisp & sulp \\
parb & plit & vuct & pult \\
seft & spem & gask & dult \\
sirm & spid & kipt & gark \\
sirk & stid & sisk & gult \\
sirl & stod & pask & solt \\
tarc & treb & bect & bult \\
teld & trob & kisp & delp \\
\hline
\end{tabular}


APPENDIX B

Nonwords Used in Experiment 2:

Target Letter in Position 4

\begin{tabular}{ccc}
$\begin{array}{c}\text { Obstruent-Obstruent } \\
\text { Cluster }\end{array}$ & $\begin{array}{c}\text { Sonorant-Obstruent } \\
\text { Cluster }\end{array}$ & Vowel Digraph \\
\hline vust & vult & veet \\
dask & dalk & deek \\
besk & belk & boak \\
fesk & felk & feek \\
sask & salk & sawk \\
pask & palk & pawk \\
tesk & telk & touk \\
gosk & golk & goak \\
voft & vort & vait \\
goft & gort & geet \\
doft & dort & deet \\
wust & wult & woat \\
\hline
\end{tabular}

(Manuscript received June 24, 1997

revision accepted for publication March 31, 1999.) 